Supplement of Ocean Sci., 17, 615-649, 2021

https://doi.org/10.5194/os-17-615-2021-supplement

(c) Author(s) 2021. CC BY 4.0 License.

(C) (i)

Ocean Science

Supplement of

\title{
FES2014 global ocean tide atlas: design and performance
}

Florent H. Lyard et al.

Correspondence to: Florent H. Lyard (florent.lyard@legos.obs-mip.fr)

The copyright of individual parts of the supplement might differ from the article licence. 


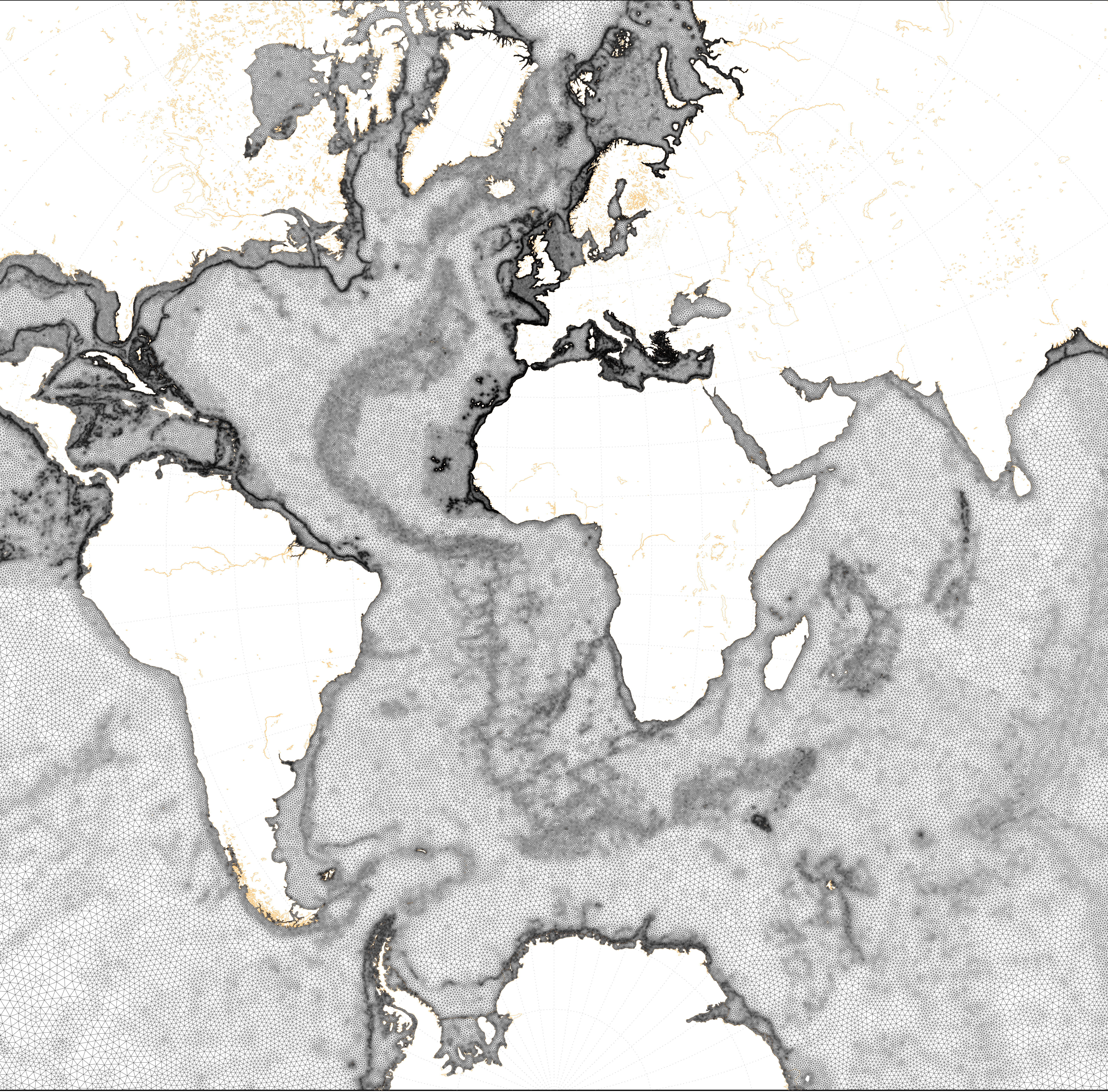






